\title{
Graphical and numerical skills in pre- and postgraduate medical students from a private university
}

\author{
Guiliana Mas', Tania Tello', Pedro Ortiz', Dafina Petrova² and Rocío García-Retamero²
}

${ }^{1}$ Institute of Gerontology, Universidad Peruana Cayetano Heredia, Lima, Perú; '2Universidad de Granada, Granada, Spain

\begin{abstract}
Introduction: Physicians and medical students need to understand numerical and graphical health data in order to provide patients with correct information. Objective: The graphical and numerical skills of medical students and residents from a private university in Lima, Peru, were determined in this investigation. Method: Cross-sectional, descriptive study. The Objective Numeracy, Subjective Numeracy and Graph Literacy Scales were applied to medical students at their two final years of medical school and to medical residents. Results: Of 169 participants, 52.07\% were sixth-year and $18.34 \%$ were seventh-year students and $29.58 \%$ were residents. Mean objective numeracy score was 7.34 , mean subjective numeracy was 34.12 and mean graph literacy was 10.35. A multiple linear regression analysis showed that Subjective and Objective Numeracy Scales highest means were associated with the male gender and training on research methodology $(p<0.05)$. Graph Literacy Scale highest means were associated with the male gender and younger age ( $p$-value $<0.05)$. Conclusion: Numeracy and Graph Literacy Scales mean scores were high in medical students.
\end{abstract}

KEY WORDS: Numeracy. Graph literacy. Medical students.

\section{Introduction}

The skills to understand graphs, as well as numerical expressions of risk such as probabilities, percentages and frequencies, is essential in the medical area. Physicians and medical students need to comprehend and understand the importance of numerical and graphical information related to health issues (e.g., risks of different diseases and treatments) in order to order for adequate information to be transmitted to patients. ${ }^{1-3}$

To make an effective decision, health personnel must be aware of the risks and benefits of different medical treatments, diagnostic tests and lifestyle modifications; however, different investigations indicate that numerical and graphical concepts are not always understood, and these are essential skills for health issues to be understood and communicated. ${ }^{4-7}$
To investigate these skills, scales have been developed in different countries such as the United States, Germany and Spain, ${ }^{8-10}$ which comply with appropriate psychometric properties to be applied in different clinical and research scenarios. ${ }^{11,12}$

The Objective Numeracy Scale, developed by Lipkus et al., ${ }^{13}$ is focused on carrying out simple mathematical operations with percentages and proportions, converting percentages into proportions, proportions into percentages and probabilities into proportions, all of them commonly used in communication for decision-making and in explaining the risks and benefits of different processes. This scale is comprised by 9 items that have been satisfactorily employed in people with low and high numeracy skills in the United States, Germany and Spain. In addition, there is a Subjective Numeracy Scale, which measures numeracy skills by means of participants' self-assessment, indicating, for
Correspondence:

Guiliana Mas

E-mail: guiliana.mas.u@upch.pe
Date of reception: 01-06-2017

Date of acceptance: 25-06-2017

DOI://dx.doi.org/10.24875/GMM.M18000132
Gac Med Mex. 2018;154:163-169

Contents available at PubMed www.gacetamedicademexico.com 
example, the degree at which they are skilled to make calculations with percentages..$^{14,15}$ This scale has shown high correlation with the Objective Numeracy Scale.

Galesic and García Retamero ${ }^{16}$ developed a new graph literacy scale with the purpose to investigate the skills for reading and understanding graphs in the context of medical decisions and for being sufficiently brief as to apply this into daily medical practice. This scale was validated and applied in national probabilistic samples in Germany and the United Stated and has been satisfactorily used in Spain. ${ }^{14}$

The present study has the purpose to determine the graph literacy and numeracy of undergraduate and postgraduate students and residents from a private university, by means of validation and subsequent application of the 3 scales: objective numeracy, subjective numeracy and graph literacy, since this is an area that has not been investigated in Peru, and by means of which the impact that entails deficient communication and information of patients in shared medical decision-making was demonstrated.

\section{Method}

\section{Site, study design and participants}

A cross-sectional, exploratory, descriptive study was carried out in a population of sixth and seventh-year medical students from the Universidad Peruana Cayetano Heredia Facultad de Medicina Alberto Hurtado, who were on rotation across the internal medicine departments of the Arzobispo Loayza and Cayetano Heredia hospitals, which are tertiary-care public hospitals of the Peruvian Ministry of Health, located at the northern area of the city of Lima; as well as of first to fourth year medical residents from all specialties of the aforementioned hospitals, after informed consent was obtained. The study was carried out in 2014.

Students were applied the objective numeracy, subjective numeracy and graph literacy scales over an average time of 20 minutes. In addition, a sociodemographic data collection form was filled for each participant.

Convenience sampling was used, according to the presence of the students at the internal medicine departments of the study hospitals during the evaluation period. The sample of sixth-year students (externs) was 88 out of a total of 100; 12 (12\%) were on rotation outside the country. The sample of seventh-year students (interns) was 31 , out of a total of $114 ; 83$ $(73 \%)$ were off internal medicine rotation. The sample of medical residents was 50 out of a total of $90 ; 40$ $(45 \%)$ were on vacation or on rotation outside the study site or the country, as shown in figure 1 .

\section{Variables}

Data were collected from the participants, including age, gender, place of origin, academic year, year of graduation from the faculty of medicine, previous knowledge on methodology or statistics and knowledge of the English language.

The Objective Numeracy Scale consists of 9 items, where simple mathematical operations are carried out using percentages and proportions. The Subjective Numeracy Scale contains 7 items whose answers are not correct or incorrect; mean calculation of alt items is obtained. The Graph Literacy Scale is comprised by 13 items and measures 3 skills related to graphical comprehension: ${ }^{16}$

- Ability to read the data, to find specific information in a graph.

- Ability to read between data, to find relationships in data as shown in graphs.

- Ability to read beyond the graphs or to make inferences and predictions with data.

\section{Ethics}

This study was approved by the Universidad Peruana Cayetano Heredia Ethics Committee.

\section{Statistical analysis}

Quantitative variables are described with means and standard deviations and qualitative variables with frequencies and percentages. For Objective Numeracy Scale assessment, the answers were analyzed by means of scores (adding up the number of correct answers, with a possible range of values from 0 to 9 ). The Subjective Numeracy Scale contains 7 items, the answers of which are not correct or incorrect mean evaluation of all items is obtained (with values ranging from 6 to 42). The Objective Graph Literacy Scale comprises 13 items; the number of correct answers was added up (values range from 0 to 13).

Analyses on reliability and validity of the construct in the Peruvian context were carried out for each scale, following the procedure adopted by the authors of the original versions. ${ }^{13-16}$ Cronbach's $\alpha$, mean 


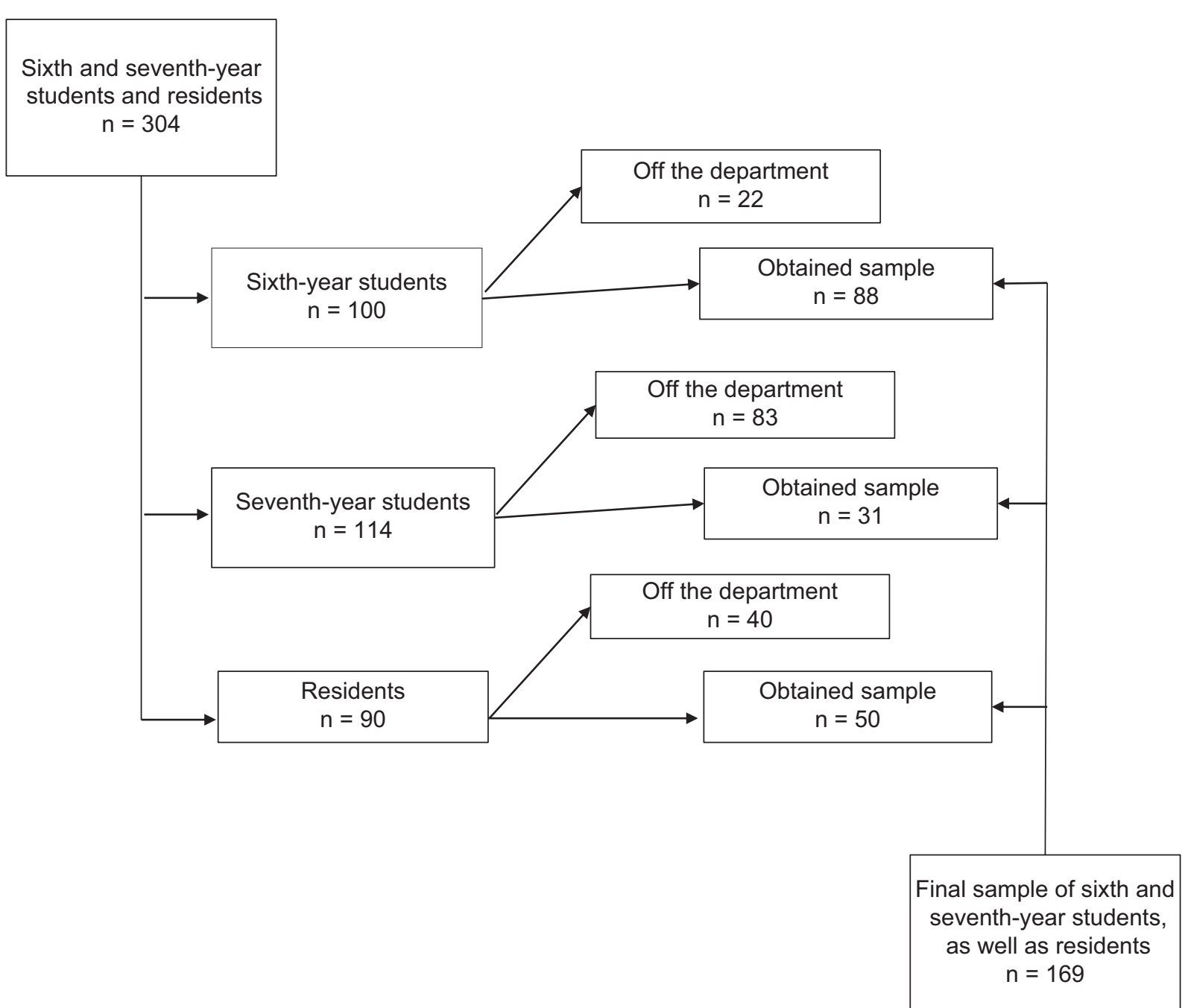

Figure 1. Selection of participants at internal medicine departments of the study hospitals.

correlation between items and mean correlation between each item and total score were calculated for all scales. Higher correlations were expected in the Subjective Numeracy Scale according to the type of scale (self-reported). In the Objective Numeracy Scale, lower correlations were expected, reflecting each item original contribution to the discriminatory capability of the scales. ${ }^{16}$ Confirmatory factorial analysis of the Objective Numeracy Scale was carried out in order to validate the established unifactorial structure of the scale. ${ }^{13}$ The Subjective Numeracy Scale and Objective Graph Literacy Scale were assessed by means of exploratory factorial analysis, since their structure was not assessed in their original versions. ${ }^{15,16}$ Each scale validity was additionally assessed by means of correlations with the other scales and related sociodemographic factors in the literature.

At the end, a multiple linear regression analysis was carried out in order to establish predictive factors for each scale. The dependent variables will be, respectively, the Objective Numeracy Scale, the Subjective Numeracy Scale and the Objective Graph Literacy Scale. The independent variable included in the study were the age, gender, previous training in methodology and student group (undergraduate and postgraduate medical students).

\section{Results}

Out of 169 participants, $52.07 \%$ (88/169) were externs (sixth-year medical students), $18.34 \%$ (31/169) were interns (seventh-year medical students) and 29.58 \% (50/169) were Universidad Peruana Cayetano Heredia medical residents who were rotating in the Arzobispo Loayza and Cayetano Heredia national hospitals. The characteristics of the sixth and seventh-year medical students and medical residents are shown in Table 1. 
Table 1. Sixth and seventh year and resident students demographic characteristics

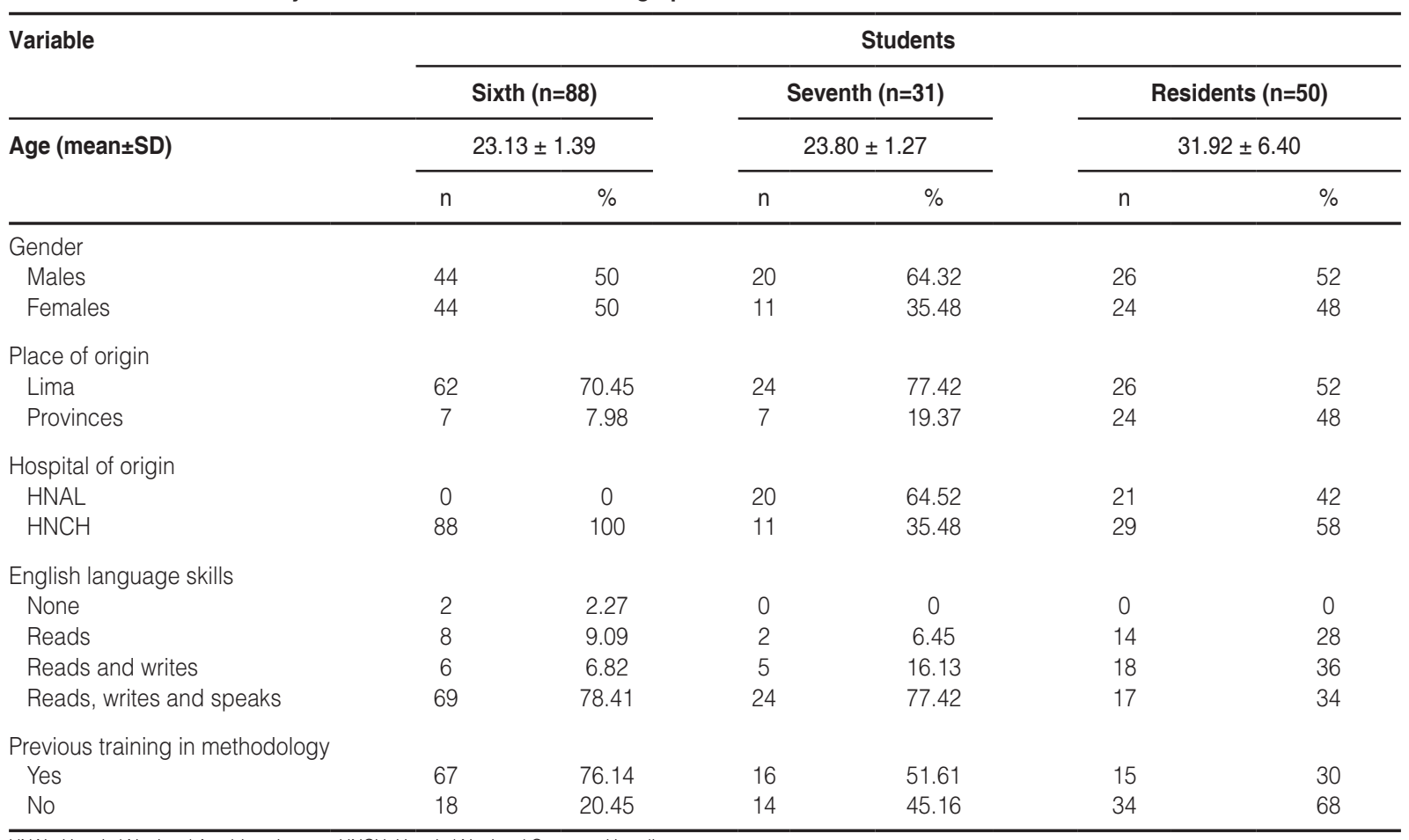

HNAL, Hospital Nacional Arzobispo Loayza; HNCH, Hospital Nacional Cayetano Heredia

Of the participating residents, $22 \%$ (11) were on training for the internal medicine specialty, $10 \%(5)$ for nephrology and $10 \%(10)$ for intensive medicine. With regard to academic years, $60 \%$ (30) were at first year, $26 \%(13)$ at second year and $14 \%(7)$ at third year of each specialty; $68 \%$ (34) of residents graduated from the Faculty of Medicine between 2006 and 2012.

In the Objective Numeracy Scale, a mean \pm standard deviation of $7.34 \pm 1.51$ was obtained, in the Subjective Numeracy Scale, $34.12 \pm 4.87$ and in the Graph Literacy Scale, $20.35 \pm 1.93$.

\section{Objective Numeracy Scale}

Item 6 was excluded from the reliability analysis because all participants formulated a correct answer. The scale showed a questionable Cronbach $\alpha$ of 0.61 . The correlation between items had a mean of $r=0.161$ and $r=0.317$ between each item and total score, which showed that each item measures a different aspect of numeracy. The unifactorial model showed a good fit with $\chi^{2}=24.42, p=0.224$ and RMSEA $=0.037(0.05$ as acceptable cutoff). ${ }^{17}$

\section{Subjective Numeracy Scale}

The scale showed a good Cronbach $\alpha$ of 0.81 . Mean correlation between items was $r=0.392$, whereas mean correlation between each item and total score was $r=0.555$, showing self-report high internal consistency. The factorial exploratory analysis identified 2 factors (eigenvalue $>1$ ), which explained $64 \%$ of variance. The first factor was composed of items 1,2 and 3 , which reflected numeracy self-assessment, and the second factor was composed of items $4,5,6$ and 7 , which reflected a preference for numeracy information. These factors are consistent with the theoretical concept of the scale. ${ }^{18}$ The scores for each factor were saved with varimax rotation as additional variables. No differences were observed between the results obtained with the additional variables and the scale original score, which is why only the original score results are shown.

\section{Objective Graph Literacy Scale}

The scale showed a Cronbach $\alpha$ of 0.66 , which is close to acceptable. Mean correlation between items was $r=0.136$ and mean correlation between each item and total score was $r=0.297$, which indicates that each item measures one different aspect of graph literacy. Item means and standard deviations were the following: ability to read data, $3.85 \pm 42$ (min. 2, max. 4), ability to read between data, $3.33 \pm 0.89$ (min. 0, max. 4), ability to read beyond data, $3.18 \pm$ 1.10 (min. 0, max. 5). 
Table 2. Scale average results by student group, gender and knowledge on methodology

\begin{tabular}{|c|c|c|c|}
\hline Variable & $\begin{array}{l}\text { Objective Numeracy } \\
\text { Scale }\end{array}$ & $\begin{array}{l}\text { Subjective Numeracy } \\
\text { Scale }\end{array}$ & $\begin{array}{c}\text { Graph Literacy } \\
\text { Scale }\end{array}$ \\
\hline \multicolumn{4}{|l|}{ Student group } \\
\hline Sixth-year students & $7.72 \pm 1.25$ & $35.14 \pm 4.98$ & $10.54 \pm 1.74$ \\
\hline Seventh-year students & $7.16 \pm 1.55$ & $33.67 \pm 3.96$ & $11.22 \pm 1.30$ \\
\hline Residents & $6.71 \pm 1.74$ & $32.44 \pm 4.82$ & $9.40 \pm 2.26$ \\
\hline Total & $7.34 \pm 1.51$ & $34.12 \pm 4.87$ & $10.35 \pm 1.93$ \\
\hline \multicolumn{3}{|l|}{ Gender } & 2 \\
\hline Males & $7.57 \pm 1.46$ & $35.43 \pm 4.63$ & $10.67 \pm 1.68$ \\
\hline Females & $7.06 \pm 1.53$ & $32.61 \pm 4.73$ & $10.00 \pm 2.13$ \\
\hline Total & $7.34 \pm 1.51$ & $34.12 \pm 4.87$ & $10.35 \pm 1.93$ \\
\hline \multicolumn{3}{|c|}{ Previous methodology training } & \\
\hline No & $6.45 \pm 1.76$ & $32.11 \pm 4.71$ & $10.01 \pm 2.11$ \\
\hline Yes & $7.87 \pm 1.05$ & $35.44 \pm 4.61$ & $10.51 \pm 1.81$ \\
\hline Total & $7.33 \pm 1.53$ & $34.16 \pm 4.91$ & $10.32 \pm 1.94$ \\
\hline
\end{tabular}

Table 3. Numeracy and graph literacy multiple linear regression analysis in Universidad Peruana Cayetano Heredia sixth-year, seven-year and resident students

\begin{tabular}{|c|c|c|c|c|c|c|c|c|c|c|}
\hline \multirow[t]{2}{*}{ Variables } & \multicolumn{2}{|c|}{ Gender } & \multicolumn{2}{|c|}{ Age } & \multicolumn{2}{|c|}{ Previous methodology training } & \multicolumn{2}{|c|}{ Externs } & \multicolumn{2}{|c|}{ Interns } \\
\hline & $\beta$ coeff. & p & $\beta$ coeff. & p & $\beta$ coeff. & p & $\beta$ coeff. & $\mathrm{p}$ & $\beta$ coeff. & p \\
\hline Objective Numeracy Scale $r^{2}=0.22$ & -0.16 & 0.02 & -0.01 & 0.31 & 0.38 & 0.00 & 0.09 & 0.46 & -0.02 & 0.84 \\
\hline Subjective Numeracy Scale $r^{2}=0.18$ & -0.28 & 0.00 & -0.02 & 0.82 & 0.24 & 0.00 & 0.17 & 0.16 & 0.04 & 0.67 \\
\hline Graph Literacy Scale $r^{2}=0.14$ & -0.18 & 0.01 & -0.25 & 0.02 & 0.03 & 0.62 & 0.07 & 0.58 & 0.19 & 0.07 \\
\hline
\end{tabular}

$r^{2}=$ percentage of variance explained by the model adjusted for dataset size

$\beta$ coefficients are standardized coefficients

The factorial exploratory analysis identified 5 factors (eigenvalue $>1$ ) that explained $60 \%$ of variance. The highest variance percentage was explained by the first factor (graph literacy, $22 \%$ ) with intermediate-high factorial loads $(0.271$ to 0.619$)$ of all items. Interpretation for the remaining factors was sought by applying several rotations. Each factor was composed of one pair of items related to the type of graph or type of answer thereof. We concluded that these factors mainly reflect common measurement variation instead of significant theoretical constructions, a typical result in this type of scales. ${ }^{13}$

Significant middle-sized correlations were observed between the three skills (objective numeracy-subjective numeracy, $r=0.44, p<0.001$; objective numeracy-objective graph literacy, $r=0.36, p<0.001$; and subjective numeracy-objective graph literacy, $r=0.24, p<0.002$ ), which demonstrated that the 3 scales measure skills that are different, but related to each other.

\section{Factors related to numeracy and graph literacy}

Table 2 shows the results by group of students, gender and previous methodology training; the highest results were obtained by sixth-year students (externs), males and students who had received methodology training during their academic education.

A multiple linear regression analysis was carried out, where the dependent variables were the Objective Numeracy Scale, the Subjective Numeracy Scale and the Graph Literacy Scale. Independent variables included in the model were the age, gender, knowledge on methodology and the student group (dummy variable). In subjective numeracy and objective numeracy, male students and those who had received methodology training obtained the highest results $(p<0.05)$. As for graph literacy, the highest scores were associated with the male gender and younger age $(p<0.05)$; however, there was no relation with previous methodology training. Interns had higher graph literacy than residents (marginally significant difference). The results are shown in Table 3.

\section{Discussion}

In the present study, the 169 sixth-, seventh-year and resident students of the Universidad Peruana Cayetano Heredia Faculty of Medicine showed numeracy and graph literacy scales high average results: $82 \%$ (7.34/9) 
for numeracy and $80 \%(10.35 / 13)$ for graph literacy ( $20 \%$ of mistakes). Some studies report $55 \%$ of mistakes in numeracy tests in nursing students, ${ }^{19}$ and that $61 \%$ of medical students adequately interpreted quantitative data even when they correctly answered a numeracy questionnaire. ${ }^{20}$ In medical students, only $69 \%$ were recorded to have correctly answered numeracy tests, ${ }^{21}$ and correct understanding of statistics in medical literature was only $41.4 \%$ in medical residents. ${ }^{22}$

In general, reliability and validity analyses of the construct indicated that the scales are valid measurements of numeracy and graph literacy. However, some important differences were identified. First, both objective scales showed less satisfactory reliability indices than those that had been found at its initial validation. These results may be due to cultural sensitivity of the scales in the Peruvian sample or, as we consider more likely, to skill differences between the general population and medical professionals. ${ }^{23}$ Both scales have been validated in the general population, including people with low levels of education, which complicates the comparison with our study sample, composed of participants with high levels of education who score high on both scales. For example, one item of the Objective Numeracy Scale showed no discrimination and was correctly answered by all participants. Similar results were found with the Objective Graph Literacy Scale: items that measure the most basic level of graphical comprehension -ability to read data (finding specific information in a graph)- were correctly answered by most participants and offered low discriminatory capacity. This means that the objective scales administered on this study have less discriminatory capacity and an improvable reliability in highly skilled populations, such as medical students. Future investigations will have to better adapt the instruments to the Peruvian context and to the medical professional context. There is another objective numeracy scale, the Berlin Numeracy Test, validated for use in populations with high levels of education and in medical professionals. This instrument has the advantage of being shorter (2 to 3 questions) and is available in Spanish (http://www.riskliteracy. org/). As for the Objective Graph Literacy Scale, in medical students or professionals, we recommend the use of an abbreviated version that includes only the items that measure the two graph literacy competences of the highest level -ability to read between data and ability to read beyond data-. This abbreviated version might significantly shorten the time required for assessment by eliminating non-discriminatory items in these populations.
Although the results include two populations at different training stages, undergraduate medical students and resident physicians on specialization, it is important for the differences to be highlighted, given that specialization programs should not neglect training and skill-building with regard to competences for the communication of decisions and risks by means of strategies that have been previously described, ${ }^{15}$ in order to this way prevent a passive posture in the shared decision-making process. ${ }^{24}$

Males and those with methodology training obtained the highest results in the Subjective Numeracy and Objective Numeracy scales, which are findings identified in other studies. ${ }^{25,26}$ This result suggests that methodology training is efficacious for numeracy skills that are relevant to medical practice to be developed and enhanced. Methodology training had a dichotomous answer, which hinders the assessment of training inherent characteristics, such as the type of training, duration of the course and obtained credits, which is one limitation of the study. However, the interest for including this variable was to identify the influence of any type of training on numeracy and graph literacy skills, since ultimately there won't be certainty on whether taught concepts were learnt on training regardless of its characteristics.

In our setting, it is more common noticing that the undergraduate curriculum is better structured than postgraduate programs, which usually are based on exposure of the trainee physician to patients of his/her specialty rather than on the development of competences related to methodology, research or communication. Although the types of studied populations can represent a continuum in medical training, sixth year, seventh year and then the residency, residents not necessarily come from the same university of undergraduate training (our sample includes only $10 \%$ of Universidad Peruana Cayetano Heredia-graduate residents), which can show the differences in the curricula of other universities with regard to training on methodology and research.

This can explain the difference between the results of the assessed undergraduate students and residents: at Universidad Peruana Cayetano Heredia, the undergraduate medical education curriculum includes research methodology, courses on biostatistics and demographics (second year), epidemiology and public health (third year), clinical epidemiology (fifth year) and research methodology (fifth and sixth year). This ultimately results in this institution being recognized as one of the leading universities in Peru and Latin America in terms of research, and one of the two universities with the highest scientific production in the country. ${ }^{19,27}$ 
Graph literacy results show that elevated scores were not only related to the male gender but also to student age. It is possible for younger students to have received better or different training that enabled them to develop their graph literacy. Alternatively, the difference between older and younger patients may be due to the time elapsed between methodology training, which may have only taken place in the undergraduate period, and the beginning of training as specialists. Consistently with this explanation, medical interns had higher graph literacy than medical residents, which demonstrates the heterogeneity there was between study participants.

This exploratory analysis allowed establishing that undergraduate students (sixth and seventh year of medical education) do have knowledge about methodology, which translates into higher results in the objective and subjective numeracy scales. Therefore, it is important establishing that, as part of their academic training, undergraduate (sixth and seventh year) and postgraduate students (medical residents) require knowledge on methodology and biostatistics for a better understanding and comprehension of numerical and graphical concepts that are essential to understanding and communication in health issues. ${ }^{17}$ Future studies should investigate how to increase numeracy and graph literacy, especially in students with serious problems for calculating and evaluating relevant data.

The limitations of our study include that a larger number of seventh-year students and medical residents could not be assessed, in order for a larger group comparison to be carried out, and that the population was restricted to a single university (in recent years, the number of faculties of medicine has increased in Peru, and a study encompassing a representative sample is required).

In conclusion, our results demonstrate that undergraduate and postgraduate Universidad Peruana Cayetano Heredia students had acceptable numeracy and graph literacy skills, which were related to demographic factors such as age and gender and academic factors such as methodology training.

\section{References}

1. Rao G. Physician numeracy: essential skills for practicing evidence-based medicine. Fam Med. 2008;40(5):354-358.
2. Elwyn G, Frosch D, Thomson R, Joseph-Williams N, Lloyd A, Kinnersley $\mathrm{P}$, et al. Shared decision making: a model for clinical practice. J Gen Intern Med. 2012;27(10):1361-1367.

3. Apter AJ, Paasche-Orlow MK, Remillard JT, Bennett IM, Ben-Joseph EP, Batista RM, et al. Numeracy and communication with patients: they are counting on us. J Gen Intern Med. 2008;23(12):2117-2124.

4. Garcia-Retamero R, Galesic M. Transparent communication of health risks: overcoming cultural differences. EE. UU.: Springer; 2013.

5. Garcia-Retamero R, Wicki B, Cokely ET, Hanson B. Factors predicting surgeons' preferred and actual roles in interactions with their patients. Health Psychol. 2014;33(8):920-928.

6. Gigerenzer G, Gaissmaier W, Kurz-Milcke E, Schwartz LM, Woloshin S. Helping doctors and patients make sense of health statistics. Psychol Sci Public Interest. 2007;8(2):53-96.

7. Wegwarth O, Schwartz LM, Woloshin S, Gaissmaier W, Gigerenzer G. Do physicians understand cancer screening statistics? A national survey of primary care physicians in the United States. Ann Intern Med. 2012;156(5):340-349.

8. Cokely ET, Galesic M, Schulz E, Ghazal S, Garcia-Retamero R. Measuring risk literacy: The Berlin Numeracy Test. Judgm Decis Mak. 2012;7(1):25-47.

9. Schapira MM, Walker CM, Cappaert KJ, Ganschow PS, Fletcher KE, McGinley EL, et al. The numeracy understanding in medicine instrument: a measure of health numeracy developed using item response theory. Med Decis Making. 2012;32(6):851-865

10. Weller JA, Dieckmann NF, Tusler M, Mertz C, Burns WJ, Peters E. Development and testing of an abbreviated numeracy scale: a rasch analysis approach. J Behav Decis Making. 2013;26(2):198-212.

11. Garcia-Retamero R, Dhami M. Pictures speak louder than numbers: on communicating medical risks to immigrants with limited non-native language proficiency. Health Expect. 2011;14(Suppl 1):46-57.

12. Garcia-Retamero R, Cokely E. Communicating health risks with visual aids. Curr Direct Psychol Sci 2013; 22(5):392-399.

13. Lipkus I, Samsa G, Rimer B. General performance on a numeracy scale among highly educated samples. Med Decis Making. 2001;21(1):37-44.

14. Zikmund-Fisher BJ, Smith DM, Ubel PA, Fagerlin A. Validation of the subjective numeracy scale: effects of low numeracy on comprehension of risk communications and utility elicitations. Med Decis Making. 2007;27(5):663-671.

15. Fagerlin A., Zikmund-Fisher BJ, Ubel PA, Jankovic A., Derry HA, Smith DM. Measuring numeracy without a math test: development of the Subjective Numeracy Scale. Med Decis Making. 2007;27(5):672-680.

16. Galesic M, Garcia-Retamero R. Graph literacy: a cross-cultural comparison. Med Decis Making. 2011:31(3):444-457.

17. Galesic M, Garcia-Retamero R. Do low numeracy people avoid shared decision making? Health Psychol. 2011;30(3):336-341.

18. Sheridan SL, Pignone M. Numeracy and the medical student's ability to interpret data. Eff Clin Pract. 2002;5(1):35-40.

19. Consejo Nacional de Ciencia, Tecnología e Innovación Tecnológica (CONCYTEC). Produccion cientifica en Perú en base a la base de datos SCOPUS de Universidades 2015. CONCYTEC Repositorio de datos. Lima, 2016. Disponible en: http://datos.concytec.gob.pe/sites/default/files/PRODUCCION_CIENTIFICA_SCOPUS_UNIVERSIDADES_2015.xISX

20. McMullan M. Exploring the numeracy skills of nurses and students when performing drug calculations. Nurs Times. 2010;106(34):10-12.

21. Johnson TV, Abbasi A, Schoenberg ED, Kellum R, Speake LD, Spiker C, et al. Numeracy among trainees: are we preparing physicians for evidence-based medicine? J Surg Educ. 2014;71(2):211-215.

22. Windish DM, Huot SJ, Green ML. Medicine residents' understanding of the biostatistics and results in the medical literature. JAMA. 2007;298(9):1010-1022.

23. Garcia-Retamero R, Hoffrage, U. Visual representation of statistical information improves diagnostic inferences in doctors and their patients. Soc Sci Med. 2013;83:27-33.

24. Trevena LJ, Zikmund-Fisher BJ, Edwards A, Gaissmaier W, Galesic M, Han PK, et al. Presenting quantitative information about decision outcomes: a risk communication primer for patient decision aid developers. BMC Med Inform Decis Mak. 2013;13(Suppl 2):S7

25. Okan Y, Garcia-Retamero R, Cokely E, Maldonado A. Individual differences in graph literacy: overcoming denominator neglect in risk comprehension. J Behav Decis Mak. 2012;25(4):390-401.

26. Schwartz LM, Woloshin S, Black WC, Welch HG. The role of numeracy in understanding the benefit of screening mammography. Ann Intern Med. 1997;127(11):966-972.

27. Huamani $C$, Mayta-Tristán $P$. Producción científica peruana en medicina y redes de colaboración, análisis del Science Citation Index 2000-2009. Rev Peru Med Exp Salud Publica. 2010;27(3):315-325. 